\title{
Development of a Novel Methodology for DC Railway Power Network Analysis Based on Participation Factor
}

\author{
Byoung-Yoon Shin*, Gilsoo Jang*, Seung-Kwon Shin**, Sung-Kwan Joo* \\ and Hansang Lee ${ }^{\dagger}$
}

\begin{abstract}
Urban DC railways have played an important role in urban transportation, and railway operation and energy management have been emphasized to be important to achieve maximum efficiency from existing infrastructure. Fast, accurate DC railway power flow analysis is required to operate a DC railway efficiently, and this paper proposes a novel methodology to analyze the DC railway power network by implementing the participation factor (PF). The PF concept consists of a correlation between the vehicle and the substation, as explained using zones based on the position of the vehicles running on the route. Then, the DC railway powerflow is calculated using the PF concept. Finally, the usability of the proposed method was validated via case studies with actual railway operation data, and we discuss some of the advantages of the suggested methodology.
\end{abstract}

Keywords: DC electric railway system, Powerflow calculation, Participation factor

\section{Introduction}

Transportation consumes a large quantity of electrical energy, and even for smart grids, smart transportation classified separately as a major concern. DC railways are large-scale transportation solutions that play an important role in urban traffic, and as urbanization accelerates, railway routes and transportation capacity need to increase.

However, there are some practical limits to doing so, such as the availability of space and power. Furthermore, the depletion of natural resources and environmental issues should also be taken into consideration. Therefore, proper vehicle operation and energy management have been further emphasized as necessary to obtain the maximum efficiency in the existing infrastructure. To this end, it is important to develop a method to more effectively calculate the powerflow in order to reflect real-time data so that operation can be carried out with various technologies, including regenerative energy, energy storage systems, substation peak load reduction, etc.

Even though a DC railway network is a simple network consisting of linear components, it actually consists of nonlinear systems since a vehicle has a constant power load. Therefore, an iterative method should be applied to determine the powerflow. The Newton-Raphson method or Gauss Seidel method are generally used for powerflow calculations $[1,2]$.

The Newton-Raphson (NR) method consists of a sparse

$\dagger \quad$ Corresponding Author: School of Railway \& Electrical Engineering,

Kyungil University, Korea. (hslee80@kiu.ac.kr)

* School of Electrical Engineering, Korea University, Korea

(\{shinby, gajng, skjoo\}@korea.ac.kr)

** Korea Railroad Research Institute (KRRI), Korea.

(skshin@krri.re.kr)

Received: July 26, 2016; Accepted: October 21, 2016 programing technique, such as a factorization algorithm, and it is popular in the analysis of large AC power systems. The NR method uses a geometric interpretation of the derivative of the slope of the tangent. Since the convergence speed of the NR method is quadratic, it is thus possible to obtain an exact approximation with fewer iterations. However, there is a difficulty in calculating the derivative, and the disadvantages of non-convergence depend on the initial value. There is also a subroutine that calculates the Jacobian matrix for every iteration, and since the Jacobian matrix is a voltage-variable function, the computational time increases.

System equation linearization allows for an iterative method, such as Gauss Seidel, to be applied to solve the equation. The advantages of using this method are that the calculation is simple and requires less memory than that for NR.

Talukda et al. suggested a direct method that changes the substation to a current model and confirmed that the Gauss iterative process is more suitable based on the limits of the initial value error, in comparison to the NR process [3]. Goodman, C.J et al. reviewed a simplified method using diakoptics on combined networks [4]. Glover, J.D et al. proposed an iterative method using the voltage-current characteristics of the vehicle [5], and Mellitt, B et al. proposed a calculation that takes into account the substation limitation, such as the overvoltage limit with regenerative energy [6]. Cai, $\mathrm{Y}$ et al. compared iterative methods for the conductance vector and current vector. This comparison indicated that the current vector is more efficient and that regenerative energy can be easily applied [2]. Various studies have investigated railway powerflow incorporating energy storage systems to reduce substation peaks as well as the efficient use of regenerative energy 


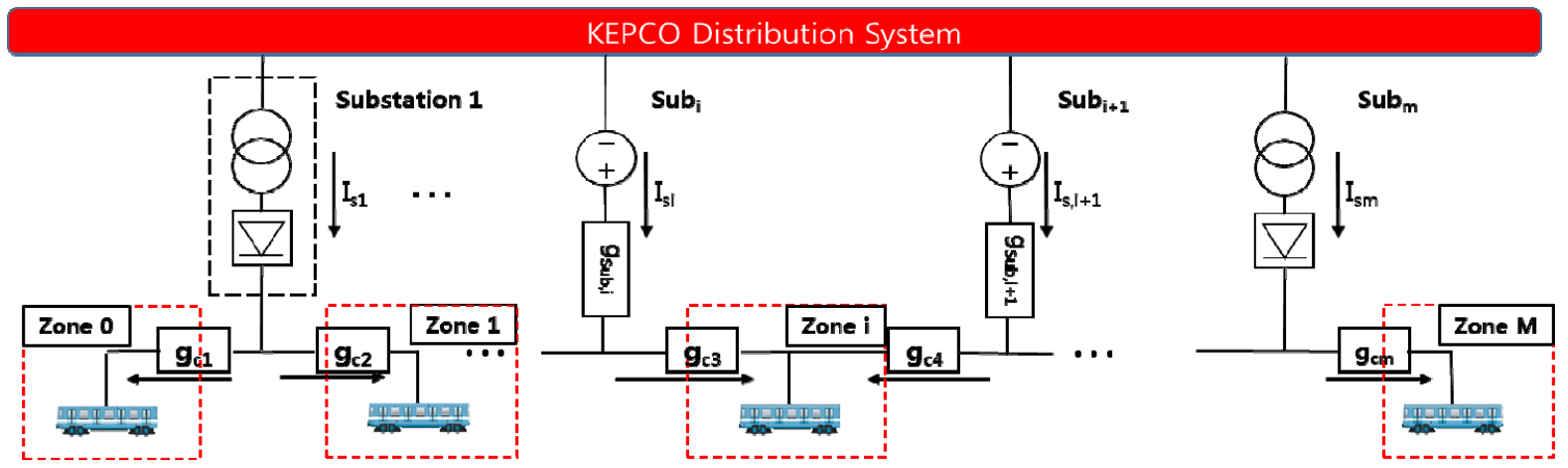

Fig. 1. Simplified model of Korean DC railway

[7 11]. AC-DC hybrid analysis methodology was suggested considering the time interval in order to analyze railway networks with distribution networks [12].

Participation Factor (PF)-based powerflow analysis is herein proposed to improve the computing speed and accuracy of the convergence characteristic, and this paper is organized as follows. Chapter 2 addresses the system configuration of a DC electric railway. The basic concept for PF and its application are presented in Chapter 3. Case studies are provided in Chapter 4, and the conclusions are described in Chapter 5.

\section{DC Railway System}

\subsection{Structure of DC railway power system}

A DC railway power system consists of a substation, catenary, vehicle and rail. Fig. 1 shows a simple railway system model. The power necessary to operate the vehicle is provided by direct current conversion from the distribution network and distributed supply to the vehicle through the catenary. There are multiple substations between the starting and final destination, and depending on the vehicle operation schedule, one or multiple vehicles can be located between substations.

In a conventional power network, only the load capacity varies with a fixed location while the location of the railway load also varies during operation. Also, the variation in the railway loads includes intermittent and regenerative characteristics when compared to conventional loads.

Therefore, a new network has to be established according to the vehicle location as time varies. Also, the characteristics of the vehicle change according to its operating status. Normally, power is consumed during acceleration, acting as a load, but it acts as a source during breaking by sending a reverse current to the network when producing regenerative energy.

\subsection{Power system configuration}

This paper assumes that the KEPCO distribution system
Table 1. Basic data

\begin{tabular}{c|c}
\hline Category & Specific data \\
\hline \multirow{4}{*}{ Operation data } & Rated voltage \\
\cline { 2 - 2 } & Dwell time \\
\cline { 2 - 2 } Substation data & Headway \\
\cline { 2 - 2 } & Source conductance \\
\cline { 2 - 2 } & Substation location \\
\hline \multirow{2}{*}{ Vehicle data } & Vehicle location \\
\cline { 2 - 2 } & Feeder impedance per $\mathrm{km}$ \\
\hline \multirow{2}{*}{ Line data } & Rail impedance per $\mathrm{km}$ \\
\cline { 2 - 2 }
\end{tabular}

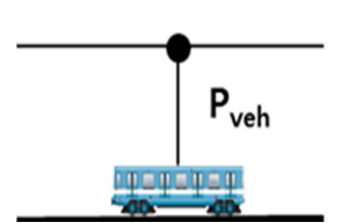

(a)

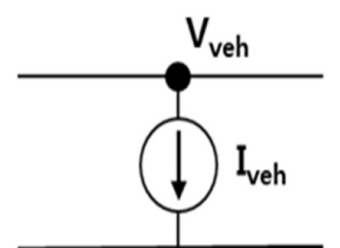

(b)
Fig. 2. Model for the vehicular load

is robust enough to build an urban DC railway power system, so the no-load voltage $\left(\mathrm{V}_{\mathrm{nL}}\right)$ supplied from the substation rectifier is constant.

The rectifier is converted to an equivalent model using a fixed value $\left(\mathrm{V}_{\mathrm{nL}}\right)$ for the voltage source and the measured source conductance, as shown in Fig. 1, to electrically separate the DC railway system from the AC distribution system. Since the vehicle acts as a constant power load, it should be expressed as a current source in order to obtain a correlation between the vehicle and the substation, as shown in Fig. 2.

Table 1 shows the data needed to construct the system equation. The network consists of substations, vehicles, the catenary and rail. Since the vehicle operates according to schedule, it is necessary to obtain vehicle location data and power consumption data as time varies.

Depending on the location of the vehicle, the conductance of the catenary between the substation and the vehicle or vehicle and vehicle varies, and it can be calculated using Eq. (1) depending on distance. 


$$
g_{C_{i}}=l_{i, i+1} \times \xi
$$

where $1_{i, i+1}$ is the line length between two electrical components, and $\xi$ is the conductance per kilometer.

\section{Participation Factor}

\subsection{Current distribution ratio}

There are several substations throughout the entire track, and the power requested by the vehicles is supplied in parallel through those. The vehicle is positioned between the end point and the starting point according to the schedule, as shown in Fig. 3.

If the vehicle is located as shown in Fig. 3(a), the current-voltage relationship between the furthest substations from the vehicle (sub1) and the following substations (sub2) is represented with Eq. (2). The current from sub2 can be expressed using Eq. (3). In Eq. (3), $\alpha_{2}$ is the coefficient of the current ratio of $I_{\mathrm{s} 2}$ to $I_{\mathrm{s} 1}$.

$$
\begin{gathered}
I_{S 2} \cdot g_{S 2}=I_{S 1}\left(g_{S 1}+g_{C, S_{1}, S_{2}}\right) \\
I_{S 2}=\frac{1}{g_{S 2}}\left(g_{S 1}+g_{C 1}\right) I_{S 1}=\alpha_{2} I_{S 1}
\end{gathered}
$$

In the same way, the current from sub $b_{i}$ can also be expressed by the current ratio, $\alpha_{\mathrm{i}}$, and $\mathrm{I}_{\mathrm{s} 1}$.

$$
I_{S i}=\frac{1}{g_{S, i}}\left\{g_{C, S_{i-1}, S_{i}} \sum_{k=1}^{i-1} \alpha_{k}+\alpha_{i-1} g_{S, i-1}\right\}_{S 1}=\alpha_{i} I_{S 1}
$$

Since the vehicle current is equal to the sum of the current from each substation, the vehicle current, $I_{\text {veh }}$, with each substation current can be expressed using the equation for Is1, as in Eq. (5). The components of the vehicle's current can thus be expressed using Eq. (6).

$$
\begin{aligned}
I_{\text {veh }}= & I_{S 1}+I_{S 2}+\cdots+I_{S m}=I_{S 1} \times \sum_{k=1}^{m} \alpha_{k} \\
& C_{\text {left }} \text { set: }\left[\alpha_{1}, \alpha_{2}, \cdots, \alpha_{m}\right]
\end{aligned}
$$

The same notation can be used to derive the current distribution for the vehicle current located in Fig. 3(b) by using Eq. (7)

Also, if the vehicle location is as shown in Fig. 3(b), the current can be calculated according to the farthest substation by using Eq. (2) (5), and this is represented in Eq. (7).

$$
\text { CD } D_{\text {right }} \text { set: }\left[\beta_{1}, \beta_{2}, \cdots, \beta_{m}\right]
$$

The vehicles are usually located between substations during operation, as shown in Fig. 3(c). In this case, the current supplied from the left- and right-side substations should be separately considered. When the vehicle is in service between $\operatorname{sub}_{\mathrm{i}}$ and $\mathrm{sub}_{\mathrm{i}+1}$, each current ratio set for
Table 2. Current distribution (CD) ratio table

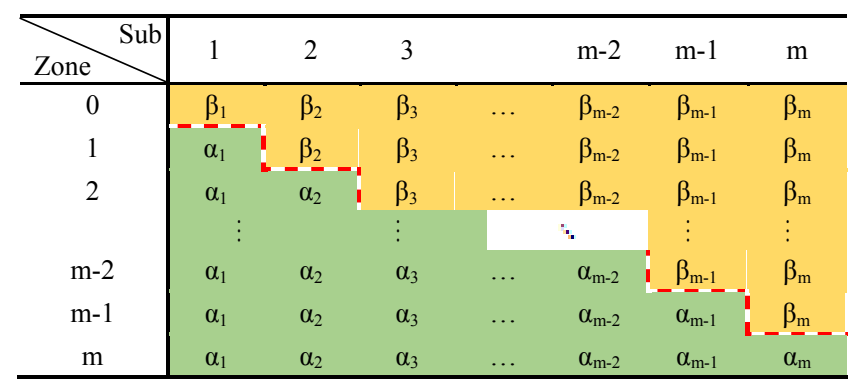

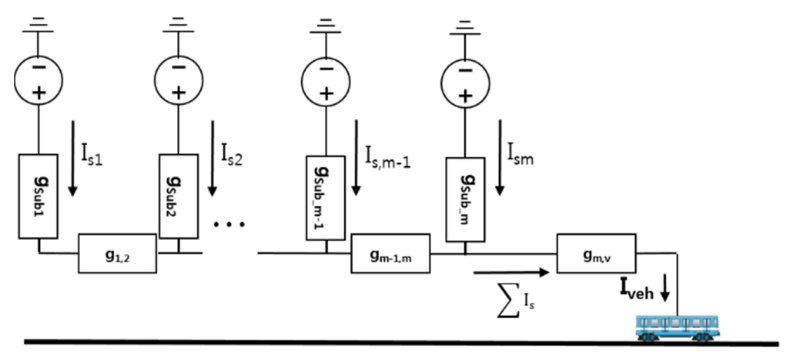

(a)

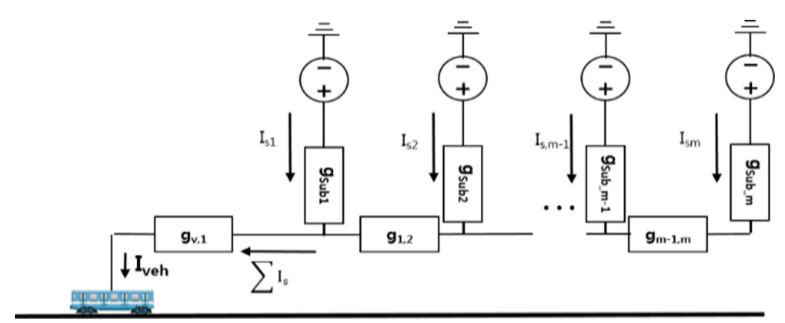

(b)

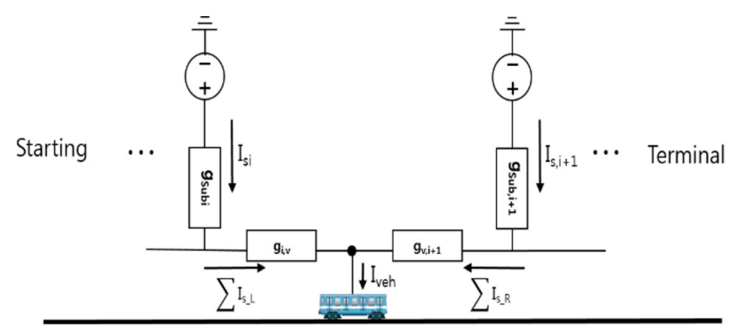

(c)

Fig. 3. DC railway location during operation time

the left side substations $\left(\operatorname{sub}_{1} \sim \operatorname{sub}_{\mathrm{i}}\right)$ and the right side substations ( $\operatorname{sub}_{\mathrm{i}+1} \sim \operatorname{sub}_{\mathrm{m}}$ ) can be derived using Eq. (6) and (7) with the $I_{S 1}$ and $I_{S m}$ functions, respectively. That is, the vehicle current, $I_{\text {veh }}$, can be expressed as the sum of the current from both sides, as shown in Eq. (8).

$$
\begin{aligned}
& I_{\text {veh }}=\left(\left[\alpha_{1}, \alpha_{2}, \cdots, \alpha_{i}\right] \cdot I_{S 1}+\left[\beta_{i+1}, \beta_{i+2}, \cdots, \beta_{m}\right] \cdot I_{S m}\right. \\
& \text { CD set: }\left[\alpha_{1}, \cdots, \alpha_{i}, \beta_{i+1}, \cdots, \beta_{m}\right]
\end{aligned}
$$

Table 2 shows the component of the current distribution ratio for the DC railway network composed of $\mathrm{m}$ substations. 


\subsection{Participation factor calculation}

In the previous chapter, we determined the current ratio for the left and right side based on the railway's location. However, we can only obtain a distribution ratio based on the end for both sides because the actual current value of the end substation for both sides is an unknown value, so the current ratio for all substations needs to be unified using one standard to calculate the actual current distribution. When the vehicle is located between the ith and $i+1$ th substations, as shown in Fig. 3(c), the relation equation is derived as Eq. (10) from the relationships between $\mathrm{V}_{\mathrm{veh}}, \mathrm{V}_{\mathrm{S}, \mathrm{i}} \mathrm{V}_{\mathrm{S}, \mathrm{i}+1}$ and the current for both sides.

$$
\begin{aligned}
& \left(\alpha_{i} \cdot g_{s i}+\sum_{k=1}^{i} \alpha_{k} \cdot g_{C, S_{i}, v}\right) \cdot I_{S 1} \\
& =\left(\beta_{i+1} \cdot g_{s, i+1}+\sum_{k=1+1}^{m} \beta_{k} \cdot g_{C, v, S_{i+1}}\right) \cdot I_{S m}
\end{aligned}
$$

Eq. (10) can be expressed as Eq. (11) by the relational expression of $\mathrm{I}_{\mathrm{Sm}}$ to $\mathrm{I}_{\mathrm{S} 1}$.

$$
\gamma=\frac{I_{S m}}{I_{S 1}}=\frac{\alpha_{i} \cdot g_{S i}+\sum_{k=1}^{i} \alpha_{k} \cdot g_{C, S_{i}, v}}{\beta_{i+1} \cdot g_{S, i+1}+\sum_{k=1+1}^{m} \beta_{k} \cdot g_{C, v, S_{i+1}}}
$$

where $\gamma$ is the current ratio of the total current from both sides.

Applying $\gamma$, the current from each substation can be represented using a value proportional to $\mathrm{I}_{\mathrm{S} 1}$. For the vehicle that is operating in Zone $\mathrm{i}$, the substation current ratio can be calculated using Eq. (12).

$$
\begin{aligned}
& I_{v e h}=\left(\alpha_{1}+\cdots+\alpha_{i}+\gamma \cdot \beta_{i+1}+\cdots+\gamma \cdot \beta_{m}\right) \cdot I_{S 1} \\
& I_{\text {veh }}=\left[\alpha_{1}, \cdots \alpha_{i}, \gamma \cdot \beta_{i+1}, \cdots, \gamma \cdot \beta_{m}\right] \cdot I_{S 1}
\end{aligned}
$$

As previously discussed, the vehicle current is equal to the sum of the substation currents. That is, each substation has its own current duty, and this current duty can be represented with a participation factor that indicates the portion of the load current or regenerative current of any specific vehicle, as shown in Eq. (15) and (16)

$$
\begin{gathered}
I_{S i}=p f_{i} \cdot I_{v e h} \\
\frac{\alpha_{i}}{\sum_{k=1}^{i} \alpha_{k}+\gamma \cdot \sum_{j=1+1}^{m} \beta_{j}} \\
\frac{\beta_{i+1} \cdot \gamma}{\sum_{k=1}^{i} \alpha_{k}+\gamma \cdot \sum_{j=i+1}^{m} \beta_{j}}
\end{gathered}
$$

Thus, the PF matrix for vehicle $\mathrm{k}$ is given in Eq. (17).

$$
\boldsymbol{P} \boldsymbol{F}=\left[p f_{1_{k}}, p f_{2_{k}}, \cdots, p f_{m_{k}}\right]
$$

The $i_{\text {th }}$ substation current is the same as the sum of the contribution for each vehicle, as in Eq. (16). The current for the whole substation can be independently obtained, and the relationship between the substation and the entire vehicle is the same as in Eq. (18).

$$
\begin{aligned}
& \boldsymbol{I}_{\boldsymbol{S i}}=\sum_{k=1}^{n} \boldsymbol{p} \boldsymbol{f}_{\boldsymbol{i}, \boldsymbol{k}} \cdot \boldsymbol{I}_{\text {veh. } \boldsymbol{k}} \\
& {\left[\begin{array}{c}
I_{S 1} \\
I_{S 2} \\
\vdots \\
I_{S, m-1} \\
I_{S m}
\end{array}\right]=\left[\begin{array}{clllll}
\mathrm{pf}_{11} & \mathrm{pf}_{12} & \ldots & \mathrm{pf}_{1, \mathrm{k}-1} & \mathrm{pf}_{1, k} \\
\mathrm{pf}_{21} & \mathrm{pf}_{22} & & \mathrm{pf}_{2, \mathrm{k}-1} & \mathrm{pf}_{\mathrm{k}, 2} \\
& \vdots & \ddots & \vdots & \\
\mathrm{pf}_{\mathrm{m}-1,1} & \mathrm{pf}_{\mathrm{m}-1,2} & \ldots & \mathrm{pf}_{\mathrm{m}-1, \mathrm{k}-1,} & \mathrm{pf}_{\mathrm{m}-1, \mathrm{k}} \\
\mathrm{pf}_{m, 1} & \mathrm{pf}_{m, 2} & & \mathrm{pf}_{m, k-1} & \mathrm{pf}_{\mathrm{m}, \mathrm{k}}
\end{array}\right]} \\
& {\left[\begin{array}{c}
I_{\text {veh } 1} \\
I_{\text {veh } 2} \\
\vdots \\
I_{\text {veh }, k-1} \\
I_{\text {veh }, k}
\end{array}\right]}
\end{aligned}
$$

\subsection{Voltage calculation}

With the substation current, we can obtain the substation voltage from the no-load voltage. Eq. (20)

$$
V_{s}=V_{n l}-g_{s} \cdot I_{s}
$$

The voltage for the $\mathrm{k}$-th vehicle located between $\mathrm{sub}_{\mathrm{i}}$ and Subi +1 can also be obtained using the PF. Based on the kth vehicle, the PF matrix and $I_{v e h}$ matrix can be expressed as follows in Eq. (21)

$$
\left[\begin{array}{ll}
P F_{11} & P F_{12} \\
P F_{21} & P F_{22}
\end{array}\right]\left[\begin{array}{l}
I_{v e h 1} \\
I_{v e h 2}
\end{array}\right]
$$

where $\mathrm{Sub}_{1} \sim \mathrm{Sub}_{\mathrm{i}}$ is row 1 and $\mathrm{Sub}_{\mathrm{i}+1} \sim \mathrm{Sub}_{\mathrm{m}}$ is row 2 of the PF matrix while $\mathrm{Veh}_{1} \sim \mathrm{Veh}_{\mathrm{j}}$ is Iveh1 and $\mathrm{Veh}_{\mathrm{k}} \sim \mathrm{Veh}_{\mathrm{n}}$ is Iveh2.

$$
V_{\text {veh } \_}=V_{s i}-\left(P F_{21} I_{v e h 2}-P F_{12} I_{v e h 1}\right)
$$

$\mathrm{V}_{\text {veh_k }}$ can be obtained as the voltage difference between $\mathrm{Sub}_{\mathrm{i}}$ in Eq. (22)

\subsection{PF based DC powerflow network analysis meth- odology}

Fig. 4 shows the DC railway powerflow process based on the PF determined above. The Gauss iteration method is suitable as a direct method, and it is herein adopted.

Step 1) Read the DC railway data and configure the railway network

Step 2) Read the location data for each railway and determine the zone of each.

Step 3) Import $\alpha, \beta$ value depending on the vehicle location and calculate $\gamma$

Step 4) Calculate PF with $\gamma$ and the current distribution ratio

Step 5) With initial values for $\mathrm{V}_{\mathrm{nl}}$ and $\mathrm{V}_{\mathrm{veh}}$, calculate the initial value of $I_{v e h}$ and calculate the substation 


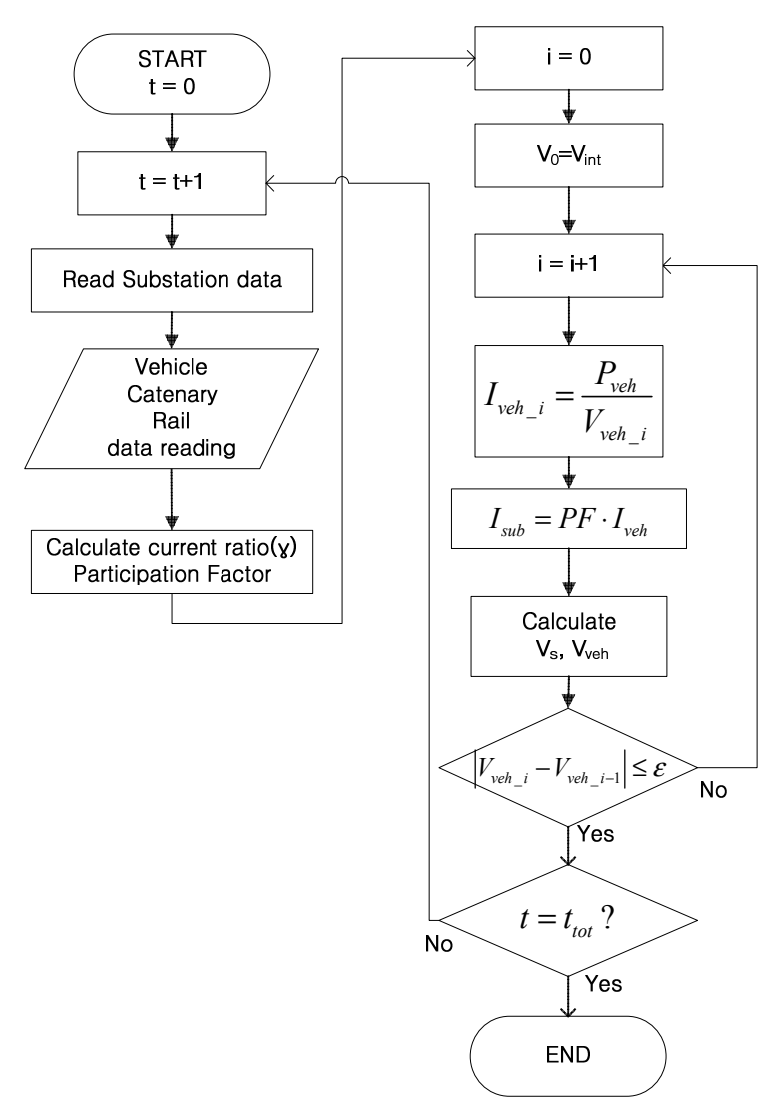

Fig. 4. Flow chart for the DC railway powerflow calculation

current using PF.

Step 6) Calculate $\mathrm{V}_{\mathrm{s}}$ and $\mathrm{V}_{\mathrm{veh}}$ with the updated substation current value. $V_{\text {veh }}$ is then applied to calculate $I_{\text {veh }}$ with the power, voltage and current relation equation.

Step 7) Iterate the process until the $\mathrm{V}_{\text {veh }}$ error is less than the specified tolerance.

\section{Case Study}

\subsection{Simulation conditions}

This section presents a case study to verify the proposed methodology. The DC railway powerflow is calculated by updating the vehicle location and power consumption data according to the actual operation schedule based on the information for Seoul Metro Line 5. The Seoul Metro Line 5 network is composed of 15 substations. Therefore, the entire area can be divided into 16 zones, and 16 railways are thus operational at the same time. We assumed that the source impedance for all substations and the feeder impedance have a particular value, as shown in Table 3 . Seoul Metro Line 5 operates with headway on the order of 5 minutes, and the length of the route is of about $49 \mathrm{~km}$. The specific data for Seoul Metro Line 5 is shown in
Table 3. Specific data for Seoul Metro Line 5

\begin{tabular}{c|c}
\hline Specific data & Seoul Metro Line 5 \\
\hline Rated voltage & $1,500[\mathrm{~V}]$ \\
\hline Dwell time & $30[\mathrm{sec}]$ \\
\hline Headway & $300[\mathrm{sec}]$ \\
\hline Number of vehicles & 16 \\
\hline No-load voltage & $1,650[\mathrm{~V}]$ \\
\hline Source impedance & $0.02956[\mathrm{Ohm}]$ \\
\hline Feeder impedance per $\mathrm{km}$ & $0.0203[\mathrm{Ohm} / \mathrm{km}]$ \\
\hline
\end{tabular}

Table 4. Geometrical location of substations

\begin{tabular}{c|c|c|c|c|c}
\hline $\begin{array}{c}\text { Sub } \\
\text { No. }\end{array}$ & $\begin{array}{c}\text { Sub. } \\
\text { Location(m) }\end{array}$ & $\begin{array}{c}\text { Sub } \\
\text { No. }\end{array}$ & $\begin{array}{c}\text { Sub } \\
\text { Location(m) }\end{array}$ & $\begin{array}{c}\text { Sub } \\
\text { No. }\end{array}$ & $\begin{array}{c}\text { Sub } \\
\text { Location(m) }\end{array}$ \\
\hline 1 & 3,612 & 6 & 20,485 & 11 & 34,326 \\
\hline 2 & 7,202 & 7 & 23,085 & 12 & 38,351 \\
\hline 3 & 10,585 & 8 & 25,085 & 13 & 40,401 \\
\hline 4 & 13,806 & 9 & 29,201 & 14 & 43,520 \\
\hline 5 & 17,509 & 10 & 32,827 & 15 & 46,904 \\
\hline
\end{tabular}

Table 3 .

The substation locations are provided in Table 4, and the zones are determined relative to these locations.

\subsection{Simulation results}

The location of each substation, the source impedance, and feeder impedance are considered as fixed parameters to determine the current distribution for the 16 zones of Seoul Metro Line 5 using Eq. (4) - (9), as shown in Table 5. For, Zones 1 and 16 which indicate the outer areas of the substation, the current distribution is determined according to Eq. (5) with their ratios between substations 15 and 1, respectively. All other zones (2-15) do not require separate computations to obtain the current distribution since they are determined directly by the base values of each substation located at the ends. For example, if a train is located within Zone 5 , it is possible to compose substations 1 to 4 with $\alpha$ values while substations 5 to 15 can be composed of $\beta$ values. By obtaining $\gamma$ from the current distribution ratio and Eq. (15) and (16), derived from the train and substation locations, it is possible to calculate the substation participation factors for each train. Table 6 includes the participation factors for $\mathrm{t}=15 \mathrm{sec}$. According to Table 6 , high participation factors are assigned to the two or three substations that are closest to the given train location.

During operation, both the location of the train and the power consumed may vary every second. Table 7 displays the location of all trains (relative to the starting point) as well as their zones and power consumed at $\mathrm{t}=15 \mathrm{sec}$. Note that negative values indicate regenerative breaking while a 0 value refers to trains in a stationary state, coasting, or at the end of operation, as for Train 16.

The suggested method is applied to calculate the results of each substation voltage, and the vehicle voltage and current are shown in Table 7.

Fig. 5 shows the voltage change for substations \#3 and 
Table 5. Current distribution set of Seoul Metro 5

\begin{tabular}{|c|c|c|c|c|c|c|c|c|c|c|c|c|c|c|c|}
\hline $\begin{array}{l}\text { Sub } \\
\text { Zone }\end{array}$ & 1 & 2 & 3 & 4 & 5 & 6 & 7 & 8 & 9 & 10 & 11 & 12 & 13 & 14 & 15 \\
\hline 1 & $15 \mathrm{E}+08$ & 27060660 & 6594807 & 1696611 & 379903.8 & 98125.1 & 27151.91 & 9849.68 & 2082.972 & 427.7125 & 183.7194 & 36.39084 & 12.5855 & 3.323924 & 1 \\
\hline 2 & 1 & 27060660 & 6594807 & 1696611 & 379903.8 & 98125.1 & 27151.91 & 9849.68 & 2082.972 & 427.7125 & 183.7194 & 36.39084 & 12.5855 & 3.323924 & 1 \\
\hline 3 & 1 & 3.465392 & 6594807 & 1696611 & 379903.8 & 98125.1 & 27151.91 & 9849.68 & 2082.972 & 427.7125 & 183.7194 & 36.39084 & 12.5855 & 3.323924 & 1 \\
\hline 4 & 1 & 3.465392 & 13.83956 & 1696611 & 379903.8 & 98125.1 & 27151.91 & 9849.68 & 2082.972 & 427.7125 & 183.7194 & 36.39084 & 12.5855 & 3.323924 & 1 \\
\hline 5 & 1 & 3.465392 & 13.83956 & 54.32985 & 379903.8 & 98125.1 & 27151.91 & 9849.68 & 2082.972 & $<27.7125$ & 183.794 & 36.39084 & 12.5855 & 3.323924 & 1 \\
\hline 6 & 1 & 3.465392 & 13.83956 & 54.32985 & 239.0397 & 98125.1 & 27151.91 & 9849.68 & 2082.972 & $\angle 27.7125$ & 183.7 & 36.39084 & 12.5855 & 3.323924 & 1 \\
\hline 7 & 1 & 3.465392 & 13.83956 & 54.32985 & 239.0397 & 876.0198 & 27151.91 & 9849.68 & 2082.972 & $<27.7125$ & 183.7 & 36.39084 & 12.5855 & 3.323924 & 1 \\
\hline 8 & 1 & 3.465392 & 13.83956 & $54.3 \overline{2} \overline{8} 85$ & Zउзȳ.ūउ̄y & 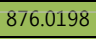 & 2996.673 & 9849.68 & 2082.972 & 427.7125 & 183.7194 & 36.39084 & 12.5855 & 3.323924 & 1 \\
\hline 9 & 1 & 3.465392 & 13.83956 & 54.32985 & 239.0397 & 876.0198 & 2996.673 & 8743.808 & 2082.972 & $\angle 27.7125$ & 183.7194 & 36.39084 & 12.5855 & 3.323924 & 1 \\
\hline 10 & 1 & 3.465392 & 13.83956 & 54.32985 & 229.0397 & 876.0198 & 2996.673 & 8743.808 & 45286.81 & 427.7125 & 183.7194 & 36.39084 & 12.5855 & 3.323924 & 1 \\
\hline 11 & 1 & 3.465392 & 13.83956 & 54.32985 & $2 3 9 \longdiv { 3 9 7 }$ & 876.0198 & 2996.673 & 8743.808 & 45286.81 & 190248.8 & 183.7194 & 36.39084 & 12.5855 & 3.323924 & 1 \\
\hline 12 & 1 & 3.465392 & 13.83956 & 54.32985 & 0.997 & 876.0198 & 2996.673 & 8743.808 & 45286.81 & 190248.8 & 446022.8 & 36.39084 & 12.5855 & 3.323924 & 1 \\
\hline 13 & 1 & 3.465392 & 13.83956 & 54.32985 & 239.0397 & 876.0198 & 2996.673 & 8743.808 & 45286.81 & 190248.8 & 446022.8 & 2365670 & 12.5855 & 3.323924 & 1 \\
\hline 14 & 1 & 3.465392 & 13.83956 & 54.32985 & 239.0397 & 876.0198 & 2996.673 & 8743.808 & 45286.81 & 190248.8 & 446022.8 & 2365670 & 6673802 & 3.323924 & 1 \\
\hline 15 & 1 & 3.465392 & 13.83956 & 54.32985 & 239.0397 & 876.0198 & 2996.673 & 8743.808 & 45286.81 & 190248.8 & 446022.8 & 2365670 & 6673802 & 27523342 & 1 \\
\hline 16 & 1 & 3.465392 & 13.83956 & 54.32985 & 239.0397 & 876.0198 & 2996.673 & 8743.808 & 45286.81 & 190248.8 & 446022.8 & 2365670 & 6673802 & 27523342 & $1.14 E+08$ \\
\hline
\end{tabular}

Table 6. Participation Factor at $15 \mathrm{sec}$

\begin{tabular}{|c|c|c|c|c|c|c|c|c|c|c|c|c|c|c|c|}
\hline $\begin{array}{r}\text { Sub } \\
\text { railway }\end{array}$ & 1 & 2 & 3 & 4 & 5 & 6 & 7 & 8 & 9 & 10 & 11 & 12 & 13 & 14 & 15 \\
\hline 1 & 0.763022 & 178779 & 043569 & .011209 & 0.00251 & 0.000648 & 0.000179 & $6.51 \mathrm{E}-05$ & $1.38 \mathrm{E}-05$ & $2.83 \mathrm{E}-06$ & $1.21 \mathrm{E}-06$ & $2.4 \mathrm{E}-07$ & $31 \mathrm{E}-08$ & $2.2 \mathrm{E}-08$ & $6.61 \mathrm{E}-09$ \\
\hline 2 & 89795 & 0.384905 & 93803 & 24132 & 0.005404 & 0.001396 & 0.000386 & 0.00014 & $2.96 \mathrm{E}-05$ & $6.08 \mathrm{E}-06$ & $2.61 \mathrm{E}-06$ & $5.18 \mathrm{E}-07$ & $1.79 \mathrm{E}-07$ & $4.73 \mathrm{E}-08$ & $1.42 \mathrm{E}-08$ \\
\hline 3 & 0.126526 & 0.438461 & 0.325663 & 0.083782 & 0.01876 & 0.004846 & 0.001341 & 0.000486 & 0.000103 & $2.11 \mathrm{E}-05$ & 9.07E-06 & $1.8 \mathrm{E}-06$ & $6.21 \mathrm{E}-07$ & $1.64 \mathrm{E}-07$ & 4.94E-08 \\
\hline 4 & 0.032372 & 0.112182 & 0.448017 & 0.312162 & 0.069899 & 0.018054 & 0.004996 & 0.001812 & 0.000383 & 7.87E-05 & $3.38 \mathrm{E}-05$ & $6.7 \mathrm{E}-06$ & $2.32 \mathrm{E}-06$ & $6.12 \mathrm{E}-07$ & $1.84 \mathrm{E}-07$ \\
\hline 5 & 09081 & 0.031471 & 0.125683 & 493392 & 0.249738 & 0.064505 & 0.017849 & 0.006475 & 0.001369 & 0.000281 & 0.000121 & $2.39 \mathrm{E}-05$ & $8.27 \mathrm{E}-06$ & $2.19 \mathrm{E}-06$ & $6.57 \mathrm{E}-07$ \\
\hline 6 & 0.002378 & 0.008239 & 0.032904 & 0.12917 & 0.568319 & 0.184324 & 0.051004 & 0.018502 & 0.003913 & 0.000803 & 0.000345 & $6.84 \mathrm{E}-05$ & $2.36 \mathrm{E}-05$ & $6.24 \mathrm{E}-06$ & $1.88 \mathrm{E}-06$ \\
\hline 7 & 0.000573 & 0.001984 & 0.007925 & 0.031111 & 0.136883 & 0.501642 & 0.218504 & 0.079265 & 0.016763 & 0.003442 & 0.001478 & 0.000293 & 0.000101 & $2.67 \mathrm{E}-05$ & $8.05 E-06$ \\
\hline 8 & 000115 & 0.000397 & 0.001585 & 0.006222 & 0.027376 & 0.100324 & 0.343188 & 0.4072 & 0.086113 & 0.017682 & 0.007595 & 0.001504 & 0.00052 & 0.000137 & 4.13E-05 \\
\hline 9 & $3.86 \mathrm{E}-05$ & 0.000134 & 0.000534 & 0.002098 & 0.00923 & 0.033826 & 0.115711 & 0.337625 & 0.379648 & 0.077956 & 0.033485 & 0.006633 & 0.002294 & 0.000606 & 0.000182 \\
\hline 10 & $1.08 \mathrm{E}-05$ & $3.74 \mathrm{E}-05$ & 0.00015 & 0.000587 & 0.002583 & 0.009465 & 0.032379 & 0.094476 & 0.489319 & 0.238711 & 0.102536 & 0.02031 & 0.007024 & 0.001855 & 0.000558 \\
\hline 11 & $2.36 \mathrm{E}-06$ & $8.16 \mathrm{E}-06$ & $3.26 \mathrm{E}-05$ & 0.000128 & 0.000563 & 0.002064 & 0.007059 & 0.020597 & 0.106677 & 0.448146 & 0.321462 & 0.063675 & 0.022021 & 0.005816 & 0.00175 \\
\hline 12 & $7.32 \mathrm{E}-07$ & $2.54 \mathrm{E}-06$ & $1.01 \mathrm{E}-05$ & $3.98 \mathrm{E}-05$ & 0.000175 & 0.000641 & 0.002193 & 0.0064 & 0.033147 & 0.139248 & 0.326456 & 0.3357 & 0.116099 & 0.030663 & 0.009225 \\
\hline 13 & $1.75 \mathrm{E}-07$ & $6.06 \mathrm{E}-07$ & $2.42 \mathrm{E}-06$ & $9.5 \mathrm{E}-06$ & $4.18 E-05$ & 0.000153 & 0.000524 & 0.001528 & 0.007916 & 0.033255 & 0.077963 & 0.413507 & 0.346169 & 0.091426 & 0.027505 \\
\hline 14 & $2.2 \mathrm{E}-08$ & $7.62 \mathrm{E}-08$ & $3.04 \mathrm{E}-07$ & $1.19 \mathrm{E}-06$ & $5.25 \mathrm{E}-06$ & $1.93 E-05$ & $6.59 \mathrm{E}-05$ & 0.000192 & 0.000995 & 0.004182 & 0.009804 & 0.052001 & 0.1467 & 0.604247 & 0.181787 \\
\hline 15 & $1.08 \mathrm{E}-08$ & $3.75 \mathrm{E}-08$ & $1.5 \mathrm{E}-07$ & $5.88 \mathrm{E}-07$ & $2.59 \mathrm{E}-06$ & $9.48 \mathrm{E}-06$ & $3.24 \mathrm{E}-05$ & $9.46 \mathrm{E}-05$ & 0.00049 & 0.002058 & 0.004825 & 0.025589 & 0.07219 & 0.297718 & 0.59699 \\
\hline 16 & $6.61 \mathrm{E}-09$ & $2.29 \mathrm{E}-08$ & $9.14 \mathrm{E}-08$ & $3.59 \mathrm{E}-07$ & $1.58 \mathrm{E}-06$ & $5.79 \mathrm{E}-06$ & $1.98 \mathrm{E}-05$ & $5.78 \mathrm{E}-05$ & 0.000299 & 0.001257 & 0.002947 & 0.015629 & 0.044091 & 0.181836 & 0.753856 \\
\hline
\end{tabular}

Table 7. Vehicle location, zone, power, voltage and current

\begin{tabular}{|c|c|c|c|c|c|}
\hline $\begin{array}{c}\text { Car } \\
\text { No. }\end{array}$ & $\begin{array}{c}\text { Vehicle } \\
\text { Location(m) }\end{array}$ & $\begin{array}{c}\text { Vehicle } \\
\text { Power }(\mathrm{kW})\end{array}$ & Zone & $\begin{array}{c}\text { V_veh } \\
(\mathrm{kV})\end{array}$ & $\begin{array}{c}\text { I_veh } \\
(\mathrm{A})\end{array}$ \\
\hline 1 & 2125.3 & 5248.9 & 1 & 1547.643 & 3391.544 \\
\hline 2 & 5290.9 & 2810.5 & 2 & 1509.702 & 1861.626 \\
\hline 3 & 8509.4 & 5196.3 & 3 & 1507.185 & 3447.686 \\
\hline 4 & 11699.5 & 3352.2 & 4 & 1548.371 & 2164.985 \\
\hline 5 & 14711.6 & 1409.3 & 5 & 1581.353 & 891.199 \\
\hline 6 & 17720.6 & 3453.4 & 6 & 1580.757 & 2184.65 \\
\hline 7 & 20904.4 & 3235.5 & 7 & 1581.617 & 2045.691 \\
\hline 8 & 24219.8 & 3027.8 & 8 & 1574.089 & 1923.525 \\
\hline 9 & 27207.5 & 3536.2 & 9 & 1526.654 & 2316.308 \\
\hline 10 & 30181.3 & 5237.1 & 10 & 1523.924 & 3436.589 \\
\hline 11 & 33264.2 & 2941.4 & 11 & 1599.046 & 1839.471 \\
\hline 12 & 36318.5 & -3862.1 & 12 & 1677.338 & -2302.52 \\
\hline 13 & 39206.4 & 5225.0 & 13 & 1591.564 & 3282.934 \\
\hline 14 & 43518.9 & 0 & 14 & 1642.651 & 0 \\
\hline 15 & 45976 & 0 & 15 & 1646.384 & 0 \\
\hline 16 & 49388 & 0 & 16 & 1647.791 & 0 \\
\hline
\end{tabular}

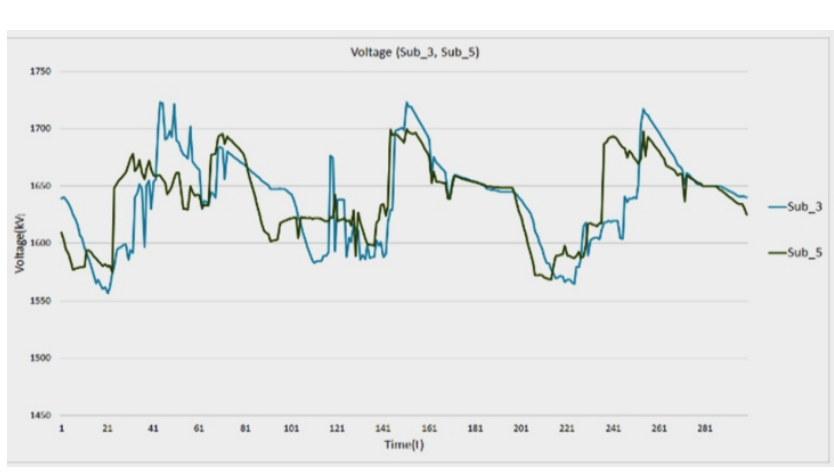

Fig. 5. Substation voltage (\#3, \#5)

\#5 during the headway (300 sec). From the substation's point of view, the substation voltage changes based on the no-load voltage due to the variation in the location and power consumption of the vehicles as time goes by. 


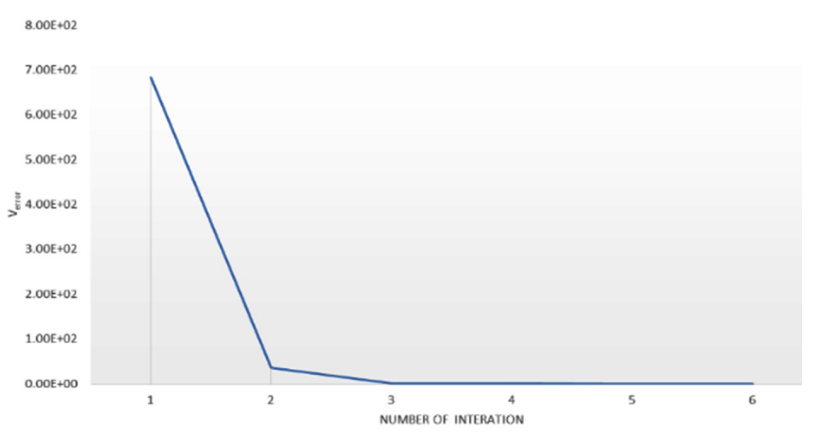

Fig. 6. Convergence of iterative procedure

Fig. 6 shows the influence that the proposed method has on the error convergence as the number of iterations varies. The results indicate that two iterations decrease the error to approximately $3.48 \mathrm{E}+1$ while 3 iterations decreases the error to approximately $2.43 \mathrm{E}-4$.

\section{Conclusion}

This paper presents a novel methodology for DC railway power network analysis based on the participation factor. The simulation in the case study is based on actual urban railway operating data, and the results show that the suggested method has a fast convergence.

Compared to existing methodology, the PF-based methodology has the following advantages.

1) If the number of substations is $m$ and the number of vehicles is $\mathrm{n}$ in the DC railway system, the conductance matrix size is $(m+n) \times(m+n)$. On the other hand, the PF matrix size is $m \times n$. Therefore, the PF matrix is smaller than the conductance matrix. If the number of vehicles increases by $\mathrm{p}, \mathrm{m}$ data is added in the case of the PF matrix while the conductance matrix is increases by 2 $(m+n+p)$.

2) For a conventional iteration method based on the conductance vector, the conductance matrix is a sparse matrix, and it is thus necessary to find the inverse matrix within the calculation process. However, the PFbased method can find a solution with an algebraic calculation without additional processes.

3) Since the vehicle moves according to the schedule, the current ratio $(\alpha, \beta)$ of the substation for the current vehicle is fixed when the vehicle is located in any zone. Therefore, the current ratio of the substation is obtained through a known value that was previously calculated. It is therefore necessary to updates the current ratio for both ends $(\gamma)$ depending on time.

Based on the methodology proposed in this paper, we will develop optimal DC railway operation that takes into account regenerative energy and ESS in substations in further studies.

\section{Acknowledgements}

This research was supported by "Energy saving technology development of urban railroad station(16RTRPB070589-04)" of the Korea Railroad Research Institute, Republic of Korea.

\section{References}

[1] Keyhani, A., A. Abur, and S. Hao, "Evaluation of powerflow techniques for personal computers,", IEEE Tran. Power Systems, vol. 4, no. 2, pp. 817-826, May 1989

[2] Cai, Y., M.R. Irving, and S.H. Case, "Iterative techniques for the solution of complex DC-rail-traction systems including regenerative braking," IEE Proceedings-. Generation, Transmission and Distribution, vol. 142, no. 5, pp. 445-452, Nov. 1995

[3] Talukdar, S.N. and R.L. Koo, "The analysis of electrified ground transportation networks," IEEE Trans. Power Apparatus and Systems, vol. 96, no. 1, pp. 240-247, Jan. 1977

[4] Goodman, C.J. and L.K. Sin. "DC railway power network solutions by diakoptics," in Railroad Conference, 1994., Proceedings of the 1994 ASME/IEEE Joint (in Conjunction with Area 1994 Annual Technical Conference), Chicago, IL, Mar. 1994.

[5] Glover, J.D., A. Kusko, and S.M. Peeran, "Vehicle Voltage Analysis for AC Railroad Electrification," IEEE Tran. Industry Applications, vol. IA-20, no. 4, pp. 925-934, July 1984

[6] Mellitt, B., C.J. Goodman, and R.I.M. Arthurton, "Simulator for studying operational and powersupply conditions in rapid-transit railways," Proceedings of the Institution of Electrical Engineers, vol. 125, no. 4, pp. 298-303, April 1978

[7] Hansang Lee, Jiyoung Song, Hanmin Lee, Changmu Lee, Gilsoo Jang, Gildong Kim, "Capacity Optimization of the Supercapacitor Energy Storages on DC Railway System Using a Railway Powerflow Algorithm," International Journal of Innovative Computing, Information and Control, vol. 7, no. 5, pp. 2739-2753, May 2011

[8] Seungmin Jung, Hansang Lee, Kisuk Kim, Hosung Jung, Hyungchul Kim, Gilsoo Jang, “A study on peak power reduction using regenerative energy in railway systems through DC subsystem interconnection," Journal of Electrical Engineering \& Technology, vol. 8, no. 5, pp. 1070-1077, Sep. 2013

[9] Hansang Lee, Seungmin Jung, Yoonsung Cho, Donghee Yoon, Gilsoo Jang, "Peak Power Reduction and Energy Efficiency Improvement with the Superconducting Flywheel Energy Storage in Electric Railway System," Physica C-Superconductivity and its applications, vol. 497, pp. 246-249, Nov.2013 
[10] Byungdoo Jung, Hyun Kim, Heechan Kang, Hansang Lee, "Development of a Novel Charging Algorithm for On-board ESS in DC Vehicle through Weight Modification," Journal of Electrical Engineering and Technology, vol. 9, no. 6, pp. 1795-1804, Nov. 2014

[11] Hansang, L., et al., "Energy Storage Application Strategy on DC Electric Railroad System using a Novel Railroad Analysis Algorithm," Journal of Electrical Engineering \& Technology, vol. 5, no. 2, pp. 228-238, June 2010

[12] Cho, Y.-S., H. Lee, and G. Jang, "Development of AC/DC Hybrid Simulation for Operator Vehicleing Simulator in Railway System," Journal of Electrical Engineering and Technology, vol. 9, no. 1, pp. 52-59, Jan. 2011

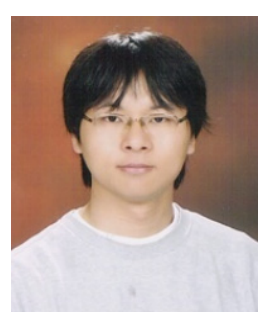

Byoung Yoon Shin He received the B.S. degree in electrical engineering from Korea University, Seoul, Korea, in 2007. He is currently working Toward a $\mathrm{Ph} . \mathrm{D}$ degree at Korea University.

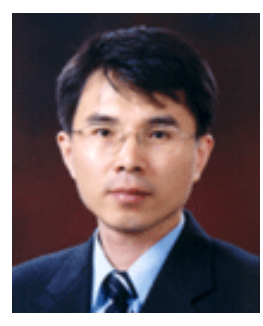

Gilsoo Jang He received the B.S. and M.S. degrees in electrical engineering from Korea University, Seoul, Korea, in 1991 and 1994, respectively, and the Ph.D. degree in electrical and computer engineering from Iowa State University, Ames, in 1997. He was a Visiting Scientist at Iowa State University from 1997 to 1998 and a Senior Researcher with the Korea Electric Power Research Institute, Daejeon, Korea, from 1998 to 2000. Currently, he is a Professor in the School of Electrical Engineering, Korea University. His research interests include power quality and power system control.

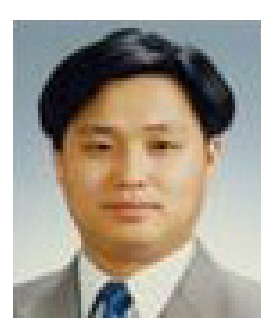

Seung-Kwon Shin He received his B.S., M.S. degree in in Electrical Engineering and $\mathrm{Ph}$. D degree in School of Electrical and Computer Engineering from Sungkyun-kwan University, Korea, in 1995, 1998 and 2001, respectively. Currently, he is a Senior Researcher in Korea Railroad Research Institute (KRRI). His research interests include a power electronic control and a railway substation including power quality, measurement and detection.

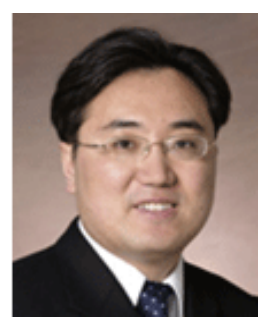

Sung-Kwan Joo He received the M.S. and Ph.D. degrees from the University of Washington, Seattle, in 1997 and 2004, respectively. He is currently a Professor in the school of electrical engineering at Korea University, Seoul, Korea.

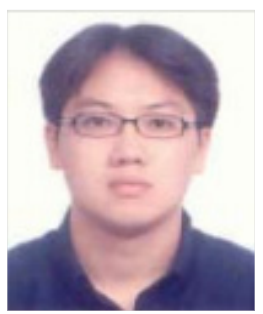

Hansang Lee $\mathrm{He}$ received $\mathrm{Ph}$. D. degree in Electrical Engineering from Korea University, Korea. He is presently an Assistant Professor of School of Electrical \& Railway Engineering at Kyungil University. 